\title{
Research on the effectiveness of education and training incentive mechanism to promote college students' Entrepreneurship
}

\author{
Chenyu Zhang ${ }^{1, \mathrm{a}, 1 \text { st }}$, Lei Zhao ${ }^{2, \mathrm{~b}, 2 \text { nd }}$, Xiao Liang ${ }^{3, \mathrm{c}, 3 \mathrm{rd}}, \mathrm{Jun} \mathrm{Li}^{4 *, \mathrm{~d}, 4 \mathrm{th}}$ \\ ${ }^{1}$ Hubei University of Chinese medicine, Wuhan, Hubei, China \\ ${ }^{2}$ Wuhan Business University, Wuhan, Hubei, China \\ ${ }^{3}$ Hubei University of Chinese medicine, Wuhan, Hubei, China \\ ${ }^{4}$ Hubei University of Chinese medicine, Wuhan, Hubei, China
}

\begin{abstract}
This paper mainly uses the methods of expert interview and questionnaire survey to collect and sort out the data and data of College Students' entrepreneurship education and training, and then carries out statistical analysis through SPSS and Excel software.Through the analysis, it is found that college students' entrepreneurship is closely related to entrepreneurship education, government entrepreneurship policies and measures, and college students' entrepreneurial activities. As the situation of college students is not consistent every year, the relevant entrepreneurial background is not the same. Only by constantly improving the entrepreneurship education policies and related measures to make them more in line with the actual situation of college students, can the entrepreneurship education policies and related measures better serve college students, thus promoting college students to enter the ranks of entrepreneurship and achieve success.
\end{abstract}

\section{Introduction}

\subsection{Research background}

With the development of society, innovation and entrepreneurship are gradually known by people, and more and more people are practicing these two words. The Chinese government has also included the entrepreneurship theme of "entrepreneurship and innovation" in its work report, which has gradually attracted the attention of various groups. In response to the national demand for "entrepreneurship and innovation", some changes have taken place in the cultivation and education of College Students' entrepreneurs. For example, it has changed the training program for college students' entrepreneurs. The innovation and entrepreneurship education and training of college students is a long-term work. In order to ensure the effective development of entrepreneurship education, colleges and universities should establish a set of scientific and effective incentive mechanism to regulate the behavior of colleges, teachers and students. However, nowadays, various problems about entrepreneurship of Chinese college students continue to appear. In many cases, the old problems have not been solved, and new problems have emerged: for example, there are some misunderstandings in entrepreneurship education and training; the research on entrepreneurship education and training is not in-depth; the practice of entrepreneurship education and training is weak; the incentive of entrepreneurship education and training is insufficient. In order to better adapt to the actual needs of contemporary economy, teaching research should also comply with the requirements of the times, and it is necessary to test and inspect the effectiveness of the incentive mechanism of entrepreneurship education and training in time.

\footnotetext{
1 Chenyu Zhang(2002 -), female, School of physical education and health, Hubei University of Chinese medicine, bachelor degree, research direction of management, Wuhan City, Hubei Province, 430065.

2 Lei Zhao(1983 -), female, associate professor, School of tourism management, Wuhan Business University, master's degree, research direction: management, Wuhan City, Hubei Province, 430046.

3 Xiao Liang(1997 -), female, School of management, Hubei University of Chinese medicine, bachelor degree, research direction of management, Wuhan City, Hubei Province, 430065.
}

4 Jun Li(1982 -), female, associate professor, School of management, Hubei University of Chinese medicine, Ph.D., research direction: management, Wuhan City, Hubei Province, 430065, corresponding author.

a2698471889@qq.com, b5943498@qq.com, c1876784024@qq.com, ${ }^{*}$ 68419785@qq.com 
The research on the effectiveness of entrepreneurship education incentive is still a new research direction in China. Can China's entrepreneurship education and training attract college students' attention and encourage them to join the ranks of entrepreneurship? Can it meet the needs of college students in the process of entrepreneurship? Can it bring real help to college graduates and promote their growth?

This paper mainly uses the methods of expert interview and questionnaire survey to collect and sort out the data and data of College Students' entrepreneurship education and training, and then carries out statistical analysis through SPSS and Excel software. The main difficulties of this paper are as follows: first, the policies on entrepreneurship education are too complicated, although we try our best to collect them, there will still be some one sidedness; second, the scope of questionnaire survey and interview covers many universities and related structures in China, and the data collection and statistics are relatively cumbersome.

\subsection{Incentive mechanism and the connotation of entrepreneurship education and training}

In English, the word "motivation" is "motivation", and its root is "motive", that is, motivation. It can be seen that motivation is closely related to motivation, including the motivation to motivate people to engage in certain activities or encourage them to do certain behaviors.

Based on this, this paper determines the subject, object, goal and incentive means of the incentive mechanism of entrepreneurship education and training. 1、 The main body of entrepreneurship education and training incentive is universities and the government; second, the object of entrepreneurship education and training incentive mechanism is college students; third, the goal of entrepreneurship education and training incentive mechanism is to provide free innovation and innovation opportunities for college students, so that college students can achieve success in Entrepreneurship and Entrepreneurship; fourth, the incentive means of entrepreneurship education and training mechanism include: government promulgated We should grasp the direction of entrepreneurship education and training from a macro perspective and supervise the implementation of relevant policies and regulations; colleges and universities can improve the relevant measures of entrepreneurship education by providing entrepreneurship training courses, holding innovative competitions and carrying out innovation and entrepreneurship business activities, so as to provide entrepreneurship education and training for College Students.

\section{The selection of effective indicators of entrepreneurship education and training policies and measures}

\section{1 government level}

In order to evaluate the effect of entrepreneurship education and training scientifically, reasonably and effectively, the following specific indicators are selected according to the effectiveness of government policies and measures.

- Content index of entrepreneurship policy. The content index of entrepreneurship policy includes the comprehensive integrity index of entrepreneurial content, the targeted index of entrepreneurial policy and measures, and the index of entrepreneurial policy support.

- The benefit index of entrepreneurship policy. The benefit indicators of entrepreneurship policy include promoting the economic efficiency of entrepreneurial team, promoting social employment, and improving the quantity and quality of innovative and entrepreneurial talents.

\section{2 university level}

This paper believes that the evaluation criteria of the effectiveness of entrepreneurship education and training are closely related to the following aspects.

-Entrepreneurship education curriculum indicators. Specifically, the curriculum indicators of entrepreneurship education include the popularity of entrepreneurship education curriculum, the richness and comprehensiveness of curriculum content, and the rationality of curriculum content.

-Implementation indicators of entrepreneurship education. The first is the diversity of teaching methods. The second is the number of entrepreneurship teachers. Thirdly, the teaching level of teachers.Finally, the management level of entrepreneurship teaching.

-Performance indicators of entrepreneurship education. The first is the improvement of students' innovative spirit and entrepreneurial consciousness. Secondly, the participation of innovation and entrepreneurship competition. Thirdly, participation in scientific research projects. Finally, the promotion degree of innovation and entrepreneurship achievements (including skills competition) is discussed.

\section{Problems in the incentive mechanism of College Students' entrepreneurship education and training}

Through the research, it is found that the incentive mechanism to promote entrepreneurship education and training of college students is insufficient. The reasons include the following aspects: 


\section{1 problems in government entrepreneurship education and training policies and measures}

\subsubsection{Poor policy pertinence}

There are many universities in China, and the economic situation and educational resources in different regions are also different. Many of the government's policies on College Students' entrepreneurship are unified and have not been able to formulate appropriate policies for specific areas. For example, if the same entrepreneurship education policies are adopted for key universities and higher vocational schools, many policies may be partial or ineffective. Due to the poor pertinence of the policy, it may lead to the later policy can not be implemented, or can not achieve the desired effect.

\subsubsection{The formulation of policies and measures lacks the participation of college students}

College students can not participate in the formulation of policies and initiatives. The national government only relies on the importance of innovation and entrepreneurship and survey data to formulate entrepreneurship education policies, but in fact, college students generally hope that they can participate in the corresponding national entrepreneurship education policies and measures.

\subsubsection{The policy content is rough but not refined}

In fact, China's entrepreneurship education policies emerge in endlessly every year. However, the implementation effect is not good because these policies and measures are not specific and detailed. This paper found that: college students with entrepreneurial intention often encounter the situation of perfunctory work of relevant government departments when they want to really understand the entrepreneurial policies and measures.

\subsubsection{Entrepreneurship education and training Policy publicity is not in place}

In the questionnaire, more than half of the college students do not know much about the entrepreneurship education and training policies or the specific operation procedures, and some college students do not even know some basic innovation and entrepreneurship policies. Although today's entrepreneurship education is strongly supported by the government or in Colleges and universities, college students have more or less received training on entrepreneurship knowledge. However, quite a number of college students will not actively understand and study entrepreneurship related policies, so it is very important to strengthen the publicity of entrepreneurship policies.

\subsubsection{Entrepreneurship education and training policy implementation is not strong}

After the field survey, we found that: many entrepreneurship education and training policies have been formulated, but it is not that entrepreneurial college students do not want to implement the policy, but that the policy implementation is too difficult. In fact, many college students want to innovate and start their own businesses. However, they find it very difficult to go through the procedures and rush to various relevant departments. Some relevant personnel do not even cooperate with the national policies, and some staff members do not even know the relevant policies and measures, which all cause difficulties for the implementation of entrepreneurship policies.

\section{2 problems of entrepreneurship education and training mechanism in Colleges and Universities}

\subsubsection{Entrepreneurship Education in Colleges and universities is not in place}

Many entrepreneurship courses are perfunctory, and even many colleges and universities set up innovation and entrepreneurship courses as optional courses, which also reflects the neglect of innovation and entrepreneurship courses in Colleges and universities.

\subsubsection{The teaching staff of innovation and entrepreneurship in Colleges and universities is not complete}

In the composition of entrepreneurship education teachers in Colleges and universities, only a small proportion of teachers have innovation and entrepreneurship experience and have participated in relevant training. Most of the innovation and entrepreneurship teachers in Colleges and universities are professional teachers or administrative personnel, such as counselors. It can be seen that the composition of teaching staff in many colleges and universities is not reasonable.

\subsubsection{University Entrepreneurship Education and social entrepreneurship environment derailment}

The social environment plays a very important role in college students' entrepreneurial enthusiasm. Many colleges and universities do attach great importance to the construction of campus entrepreneurship environment, such as holding various entrepreneurship competitions and encouraging college students to participate, setting up entrepreneurial clubs and holding regular lectures. However, it is not enough to cultivate the campus environment for college students to start their own businesses. It is an objective problem whether the entrepreneurship education in Colleges and universities can be integrated with the social entrepreneurship environment. 
3.2.4 The achievements of entrepreneurship education in Colleges and universities can not be transformed into practical innovation and entrepreneurship ability

In this paper, through field interviews, we found that many college students have had good entrepreneurial projects because of their internal entrepreneurial willingness and the corresponding impact of entrepreneurship education in Colleges and universities. However, when college students really want to implement their own entrepreneurship projects, they find that many events are consistent with or even opposite to the knowledge of innovation and entrepreneurship courses and textbooks. This reflects that there is a certain separation between the entrepreneurial knowledge learned by college students and the actual entrepreneurial ability that college students need to start their own businesses in the society. That is to say, the achievements of innovation and entrepreneurship education have not been transformed into real practical entrepreneurial ability. It can also explain why some college students do well in school, but they often fail in the early stage of entrepreneurship.

\section{Countermeasures and suggestions on improving the incentive mechanism of entrepreneurship education and training}

\section{1 suggestions to the government}

\subsubsection{Establish an incentive mechanism system with government as the leading factor and full participation}

An incentive mechanism system is established under the leadership of the central and local governments, based on entrepreneurship education, supported by entrepreneurship policies, and fully participated by universities, enterprises, social groups and other social sectors. From the system level, the responsibilities and obligations of the central government and local governments at all levels in the process of establishing this support system are clearly divided. By means of law and administration, the central government and macroeconomic means. According to the central government's overall plan and strategic intention, the local government formulates corresponding specific measures and puts them into practice. At the same time, we will expand the scope of the main body involved in the construction of this system to the important social responsibilities of all walks of life such as all universities, enterprises and social organizations.

\subsubsection{Strengthening the incentive of entrepreneurship policy}

The government should strengthen entrepreneurship policy incentives, including: (1) financial incentives for entrepreneurship, including the establishment of financial balance special subsidies and subsidies, compensatory state student loans, the issuance of government guaranteed entrepreneurial loans, the establishment of venture funds, tax reduction and exemption, preferential registration funds and other measures. (2) Entrepreneurship service incentives include lowering the entry threshold of entrepreneurship market, simplifying the administrative examination and approval procedures of College Students' entrepreneurship, providing "onestop" entrepreneurship service, establishing university students' entrepreneurship project library, holding entrepreneurship project exhibition and promotion and guidance activities. (3) Social security incentives for entrepreneurship include social security incentives (improving social insurance, social assistance, psychological comfort, etc.), economic security incentives (commercial insurance, loan relief, risk compensation funds, etc.) and legal security incentives (establishing legal aid, credit protection, etc.) to eliminate the worries of entrepreneurial failure for college students.

\subsubsection{Strengthening the pertinence and legality of entrepreneurship policy}

On the one hand, the government needs to consider the individual differences in different regions, and formulate targeted entrepreneurship education and training policies in different regions. On the other hand, the government must formulate the corresponding levels of entrepreneurship education policies according to different levels of colleges and universities, for example, the entrepreneurship education and training policies of key universities and higher vocational schools should be different. Making corresponding policies according to different actual situations can make the policy content more in line with the local actual situation and is more conducive to the implementation of the later policies.At the same time, entrepreneurship policy should be legislated to strengthen its authority and execution.

\subsubsection{Let college students participate in the formulation of government entrepreneurship education and training policies}

Some government officials think that it is not necessary for college students to participate in the formulation of entrepreneurship policies, but through field research, many college students hope to participate in the formulation of entrepreneurship policies. Many college students think that entrepreneurship education and training policies are closely related to every college student, and they should participate in the formulation of these entrepreneurship policies which are closely related to themselves. Therefore, the relevant government 
departments can allow college students to participate in the formulation of entrepreneurship policies at different levels. In this way, it can not only make the entrepreneurship education and training policy more targeted, but also reflect the actual needs of contemporary college students entrepreneurs, and can play a certain role in publicity, so that more college students participate in entrepreneurship. Tiktok's participation in the formulation of government entrepreneurship education and training policies can be diversified and take into account the characteristics of young college students, such as online questionnaires, official account numbers of WeChat, and vibrato.

\subsubsection{Strengthening the publicity of entrepreneurship education and training policy, to create a good entrepreneurial atmosphere}

The proportion of College Students' self employment has not reached the expectation of the national government and relevant departments, which must be due to the inadequate publicity of national policies. The publication of a policy should first make its audience understand it. Only after the college students understand the content of the entrepreneurship policy, can we stimulate their interest in Entrepreneurship and further guide them to engage in entrepreneurship. The relevant government departments must strengthen the publicity and promotion of entrepreneurship education and training policies for college students. Only when college students know the entrepreneurship policy, can they refer to the relevant entrepreneurship policy when they have entrepreneurial needs, and then the entrepreneurship education and training policy can be implemented.

\section{2 suggestions for colleges and Universities}

\subsubsection{Establishing a perfect system of entrepreneurship education and training}

According to the field survey, many college students do not fully agree with the curriculum system and teaching management of colleges and universities. They think that the curriculum system of colleges and universities lays emphasis on theory and practice, entrepreneurship education is seriously lacking or mere formality, and the teaching management in Colleges and universities is too rigid and inflexible. Although colleges and universities are also trying to change this situation, but little effect. If colleges and universities want to establish a sound entrepreneurship education and training system, they should do: first of all, colleges and universities must clear their own training objectives, and then according to the different objectives of talent training in Colleges and universities, to develop their own entrepreneurship education and training plan. It is urgent to make clear the goal. Only when the goal is clear can colleges and universities make similar adjustments according to the goal. Secondly, colleges and universities should reform the entrepreneurship curriculum system, including: (1)
Innovative teaching methods. College students are a very young group, and they can adopt novel teaching methods that they are willing to accept, such as barrage teaching, wechat, rich media, etc. The teaching place does not have to be rigidly confined to the classroom. It can go out and carry out on-the-spot teaching in the broad world outside. (2) Enrich the course content. The content of the course is the main source of College Students' innovation and entrepreneurship knowledge, and it is very important to enrich the innovation and entrepreneurship curriculum system. The content of the course can be diversified and practical, and various practical knowledge needed in the entrepreneurial process can be added, such as the writing of business plan, tax law, financial accounting, business etiquette, etc., and even can be shared by successful entrepreneurs on site. (3) Strengthen entrepreneurship practice training. No matter how rich the theoretical knowledge of entrepreneurship, it is still impossible to lack practical experience. Entrepreneurship courses in Colleges and universities should be combined with entrepreneurship practice, such as the establishment of an entrepreneurial Industrial Park on campus, which connects with enterprises and government departments in society, so that students can directly practice and accumulate experience.

\subsubsection{Strengthening the construction of entrepreneurial teachers}

Only the excellent and experienced tutors can cultivate excellent entrepreneurial students. The following measures can be taken to strengthen the construction of entrepreneurial teachers: (1)encourage teachers to carry out project cooperation and post practice in entrepreneurial industrial parks in the society; (2)invite senior managers and experts with rich practical experience in entrepreneurship to carry out special training for college teachers; (3)establish a scientific and effective teaching quality assessment system to assess teachers regularly.

\subsubsection{Encourage colleges and universities to establish college students' entrepreneurial Club}

Encouraging colleges and universities to establish college students' Entrepreneurship club mainly includes: (1) establishing tutor team according to different entrepreneurial subjects and contents of entrepreneurship projects, creating different training systems to achieve more accurate guidance; (2) some college students come from rural areas and can combine rural entrepreneurship with poverty alleviation. Colleges and universities help to screen and recommend entrepreneurial projects. According to the industrial poverty alleviation policy in targeted poverty alleviation, the projects with less investment and lower risk are selected to local farmers with difficulties, so as to organically integrate poverty alleviation and rural entrepreneurship. At present, a number of colleges and universities have established "entrepreneurial home", there are many entrepreneurial 
teams and related entrepreneurship projects interested in rural areas.

\subsubsection{Strengthening the transformation of University Entrepreneurship Industrial Park to achievements and realizing the "learning, research and production" process}

University Entrepreneurship Industrial Park is the base of entrepreneurship practice for college students. If the knowledge learned is applied to practice, if the achievements are formed, the enthusiasm and confidence of college students will be greatly improved. Colleges and universities can join hands with the government and enterprises to build a university entrepreneurship Industrial Park. Through government policy support and enterprise fund support, actively promote the incubation of College Students' entrepreneurship projects, realize the organic combination of learning, research and production, and accelerate the local transformation of scientific and technological achievements.

\section{Conclusion}

In today's society, competition among countries is intensifying. Innovation and entrepreneurship is very important to enhance a country's international competitiveness and comprehensive national strength. As an important subject in innovation and entrepreneurship, college students should shoulder the responsibility of rejuvenating the country. As an incubator for cultivating college students, colleges and universities should further strengthen the construction of entrepreneurship curriculum education system, innovation and entrepreneurship practice system, entrepreneurship education teacher team system, entrepreneurship education mode system and entrepreneurship education effectiveness evaluation system, so as to cultivate multidirectional entrepreneurial talents with outstanding innovative thinking, extraordinary entrepreneurial skills and superior entrepreneurial practice ability.

In this paper, we use the methods of questionnaire survey and field survey to collect data from universities and institutions across the country, and sort out the data. The results show that the implementation effect of entrepreneurship education and training mechanism for Chinese college students is not good, and there are many problems. To establish an effective incentive mechanism for entrepreneurship education and training, the government, universities, enterprises and college students should make joint efforts.

\section{References}

1. Zheng Dan, "Research on the construction of university students' innovation and entrepreneurship incentive mechanism under the background of" mass entrepreneurship and innovation "[J]. Urban society, 2016 (17): 61-62

2. Huang Huizi. Research on incentive mechanism of College Students' innovation and entrepreneurship [D]. Anhui University, 2014:2

3. Shi Muhua, Qu Changzhu, research on College Students' innovation and entrepreneurship and its incentive mechanism $[\mathrm{J}]$. Journal of Changchun Institute of education, 2015 (23): 35-36

4. Zhu Weiguo, Zhou Qunhua. Research on the goal orientation of entrepreneurship education in Higher Vocational Colleges [J]. Vocational education communication, 2012 (01): 15-20

5. Sun Qingzhu: Entrepreneurship Education for contemporary college students [M], Beijing: National Defense Industry Press, 2011.6:5 